\title{
The influence of reflection on the process of personality socialization in adolescence
}

\author{
Faizura Semenova, Fatima Salpagarova*
}

Aliev Karachay-Cherkess State University, Faculty of psychology and social work, 369202 Karachaevsk, Russia

\begin{abstract}
Reflection is analyzed as a process affecting the development of personal qualities, especially reflection in adolescence. The features of social adaptation in adolescence, the importance and the role of reflection in the process of socialization of adolescents. The article presents the results of empirical research, which confirm our hypothesis about the influence of reflection on the process of socialization in adolescence. The aim of our study is that active reflection in adolescence largely has a positive impact on the process of socialization, by means of introspection, adequate perception of oneself and one's personal characteristics, strengthening one's own positions, acceptance of one's role, selfactualization.
\end{abstract}

\section{Conduct}

\subsection{Features of reflexive processes in adolescence}

In modern psychological research, scientists are increasingly paying attention to the phenomenon of "reflection", emphasizing its role and importance in various sociopsychological processes. Particular attention is paid to the study of the structure of reflection as a scientific category, the mechanisms of its functioning and influence on the formation and the development of personality. Reflection influences such constructs that are important in the development of personality: the processes of self-consciousness, selfreflection and communication. Reflection is the basis of positive and stable interpersonal contacts. Formed reflexive competence contributes to the formation of intra-personal harmony, mobilization of volitional potential, the possibility of personal control over their own emotions. Reflexivity as a personal education is proof that repeatedly investigated in psychological science category "thinking" is not limited in possibilities [1]. The processes of reflection provide a unique opportunity for self-actualization and self-education of the processes of mental activity of the individual [2]. Reflection contributes to a concerted action of partners in joint activities [3,4]. Reflection acts as a unique ability of a person to introspection, rethinking his own actions [5]. This phenomenon determines the

\footnotetext{
${ }^{*}$ Corresponding author: uchkylan@yandex.ru
} 
communicative qualities of personality, such as compassion, non-judgment attitude, congruence, insight, and tolerance [6].

In D. I. Feldstein's concept of adolescence (2006), reflection is described as one of the main mechanisms of self-consciousness of a teenager's personality, which mobilizes the possibilities of consciousness to perceive one's own needs and accept the needs of others [7]. Especially important for the maturing person is the interpersonal relationship and social ties that define its social role [8]. Reflection in adolescence is not limited to intrapersonal experiences, in conjunction with the transformation of consciousness and acceptance of themselves as a member of society and community in society, and the development of the ability to understand and accept other members of society. Everything a teenager learns about himself as a person in the process of communication and interaction with others is mediated by reflection [9]. Reflection in adolescence, defining the center of self-regulation, on the one hand gives freedom of action, and on the other hand imposes a certain framework corresponding to individual abilities, allowing you to be the subject of your own life [10]. The need of a teenager to achieve the desired position among peers is likely to cause aggressive behavior, indiscipline, disobedience of parents, and even offenses. Reflection is a kind of link between the inner needs of a teenager with personal characteristics, qualities and abilities [11]. The process of adaptation in a new adult role to the external conditions of society is less painful with the activation of reflexive processes [12]. Reflection in adolescence leads to an inner awareness of their actions and actions [13].

\subsection{The effect of reflection on socialization in adolescence}

Unrealized socialization and social adaptation inevitably leads to maladaptation of a teenager. In this age period, the process of socialization is complicated by the maximalism inherent in adolescents, reflected in the apparent discrepancy between personal opportunities and individual aspirations [14]. The process of socialization is closely related to self-esteem of the individual. Self-esteem as an element of self-awareness can largely determine the personal comfort of a teenager or discomfort, expressed in self-perception in a social environment [15]. In the process of becoming himself as a social person, a teenager turns mainly to himself. Awareness, evaluation and analysis of their own individual personal qualities and abilities and the possibility of applying them in society appears with the possibility of reflection [16]. Reflection is one of the main psychological neoplasms of adolescence [17]. Reflective processes are activated by the need for socialization, which is especially acute in adolescence. The basis of social adaptation and the formation of longterm social relationships is reflection, since with the transition of adolescent self-awareness to a new level, it is mediated to a greater or lesser extent by reflection.

\section{Problem statement}

Socialization in adolescence becomes one of the main processes, since the acceptance of oneself as an adult becomes the main issue for a teenager. If the social role of the child is sufficiently familiar to the teenager, then to take the position of an adult he needs, mainly, to know himself, evaluate and accept his own personal qualities, turning to himself. Nowadays, the features of reflexive processes of functioning, their formation in the process of socialization and their interdependence in modern science have not been studied enough, although, of course, the analysis of scientific psychological and pedagogical literature shows that the influence of reflection on one of the most important problems of adolescence-socialization, is obvious. 


\section{Research questions}

It appears that the level of development of reflection is influenced by the process of socialization and social adaptation of the teenager, self-awareness - an essential personal education having a significant impact on the regulation of private behavior in society, and defining its social role.

\section{The purpose of research}

To investigate the features of reflection influence on the processes of socialization and social adaptation in adolescence.

\section{Method of research}

Test of reflection (method of diagnosis of the level of reflexivity, questionnaire Karpov A.V.).

Multilevel personal questionnaire "Adaptability" (Maklakov A. G., S. V. Chermenin). Test "Levels of socialization" ( version Mokshantsev R. I.).

The study was conducted in the 2017-2019 biennium. the study involved 120 respondents, students in grades 7-9 SECONDARY "Gymnasium S. Friendship" and KGO MBOU "school №3" named after H. W. Bogatyrev. All respondents who participated in the study gave their consent.

Methods of mathematical statistics: arithmetic mean, Pearson correlation coefficient.

\section{Summary}

Analysis of the data obtained during the empirical study showed that the level of reflection in adolescence has a significant impact on socialization. The results allow us to conclude that a high level of reflection in adolescence provides a high level of adaptability and socialization of adolescents.

Our research took place in several stages:

1. Analysis of theoretical literature in order to identify research vectors: the main correlates of the problem; selection of methods of empirical research, distribution of respondents to the control (KG) and experimental (EG) groups.

2. The ascertaining part of the experiment, which included the study of individual measures of reflexivity (levels), as well as the evaluation of the process of socialization and social adaptation of adolescents. The results of the experiment were used to analyze the influence of reflection on the process of socialization of the individual in adolescence.

The level of individual measure of reflexivity was diagnosed by Karpov A.V.'s questionnaire "Level of development of reflexivity"; methods: "Multilevel personal questionnaire" Adaptability "(A. G. Maklakov, S. V. Chermyanin) and" Levels of socialization " (version Mokshantseva R. I.) revealed quantitative parameters of the process of socialization and social adaptation of adolescents.

3. The formative stage of the experiment included a comprehensive work with parents, students, teachers on the influence of reflexivity of personality on the process of socialization. The program of formation of reflexive competence "I know myself" was realized with pupils [18]. The program includes classes in cycles: 1) educational Materials for parents and teachers (4h.); 2) Training on the formation of the personality of a teenager "I - personality" (16h.); 3) Training on the regulation of emotional and volitional sphere "I 
can control myself" (5h.); 4) Training on social adaptability "I and the world" (10h). The work was carried out with teenagers (experimental group), with parents and teachers.

4. The control stage of the study allowed to estimate the degree of reflection influence on the process of personality socialization in adolescence.

According to the data obtained, the subjects are divided into 3 groups depending on the level of development of reflexivity: low, medium and high level of development of reflexivity. In the experimental and control groups, the data obtained had a small spread of $1-3 \%$ and amounted to: according to the method, the level of reflection in the experimental ( $9 \%$ high, and $32 \%$ average, 59\% levels) and the control (8\% high 33\%, average, $59 \%$ levels) groups.

As a result of the carried out techniques, for studying of process of socialization and social adaptation of teenagers, the following data were received: by a technique of adaptabilityexperimental (10\%high, and $31 \%$ average, $59 \%$ levels), control (9\%high, and $33 \%$ average, $58 \%$ ) groups; according to the method the level of socialization-experimental $(7 \%$ high, and 35\% average, 58 levels) and control (9\% high, and 34\% average, 57\% levels ) groups.

Thus, comparing the results, we can state that the relationship between the level of reflexivity and socialization and social adaptation is revealed: in adolescents in both groups, who have a high level of reflexivity (10\% - KG and 9\% EG), a high level of social adaptation ( $9 \% \mathrm{KG}, 7 \% \mathrm{EG})$ is revealed. But, in General, in the sample the percentage of respondents who showed a high and average level of the studied indicators was less than $50 \%$.

The results of the first stage of the study, in the experimental and control groups, in which all three methods were carried out, showed: according to the method, the level of reflection in the experimental (19\% high, and $42 \%$ average, $39 \%$ levels) and control (18\% high, and $43 \%$ average, $39 \%$ levels) groups, according to the method of adaptability-experimental ( $21 \%$ high, and $41 \%$ average, $38 \%$ levels), control (19\% high, and $43 \%$ average, 38 levels) groups, according to the method the level of socialization-experimental $(17 \% \mathrm{high}$, and $45 \%$ average, 38 levels) and control (20\% high, and 44\% average, $36 \%$ levels) the Ratio of results for all methods in both groups did not exceed $3 \%$, which is not a significant difference and allowed to move to the next stage of the experiment.

After carrying out research procedures of the forming stage with experimental group repeated psychodiagnostic research of influence of reflection on process of socialization of the personality in teenage age was carried out.

At the control stage of the study, a psychodiagnostic study of the levels of reflection formation, adaptability and socialization of adolescents was conducted, which showed significant changes in the experimental group compared to the control group: according to the method, the level of reflection in the experimental group (39\% high, and $53 \%$ average, $8 \%$ levels) and control (19\%high, and $43 \%$ average $38 \%$ levels) groups, according to the method of adaptability-experimental (35\% high, and 56\% average, 9\% levels), control ( $18 \%$ high, and $46 \%$ average, $36 \%$ levels) groups, according to the method the level of socialization-experimental (37\%high, and 54\% average, 9\% levels) and control (22\% high, and $44 \%$ average, $34 \%$ levels) groups.

To identify the relationship between the studied parameters of "reflection" and "socialization", the data were processed by statistical processing. Pearson correlation coefficient was calculated, which allowed to determine the presence of a direct linear relationship between the quantitative indicators of the levels of reflection formation and the level of socialization and adaptation of adolescents. It turned out that a high level of reflexivity correlates with a high level of socialization and adaptation (0.7), an average level of reflexivity correlates with an average level of socialization and adaptation (0.7), a low level of reflexivity correlates with a low level of socialization and adaptation (0.5).

This feature was manifested in both experimental and control groups. 


\section{Conclusion}

The phenomenon of "reflection" is a unique ability of a person to analyze his own personal qualities, his actions and himself as a subject of his activity. Reflexive processes are especially relevant for adolescence, because adulthood entails a change of role in the social environment, actualizing the problem of the success of socialization of the maturing person. To determine their position in society in a different role, the teenager requires mainly knowledge and acceptance of themselves. The study shows a significant influence of reflection on the process of socialization in adolescence.

The following statistically confirmed facts were revealed:

1) the level of reflexivity and the level of socialization and social adaptation in the experimental group increased;

2) a positive correlation between the level of reflexivity and the level of socialization and adaptation of adolescents was revealed: a high level of reflexivity correlates with a high level of socialization and adaptation (0.7), an average level of reflexivity correlates with an average level of socialization and adaptation (0.7), a low level of reflexivity correlates with a low level of socialization and adaptation (0.5).

Thus, the level of reflexivity of a teenager directly affects the level of socialization and social adaptation of a teenager, regulating his behavior in society and determining his social role.

\section{References}

1. K. Rogers, The perspective on psychotherapy. Becoming a human (Progress, Moscow, 1994)

2. B.G. Ananyev, Man as a subject of knowledge (Prosveshchenie, Moscow, 2013)

3. G.P. Shchedrovitsky, Selected works (School of Cultural Policy, Moscow, 1995)

4. V.A. Lefebvre, Conflicting structures (Soviet radio, Moscow, 1973)

5. A.G. Asmolov, Psychology of personality (MSU publishing House, Moscow, 2005)

6. B.F. Lomov, Methodological and theoretical problems of psychology (Nauka, Moscow, 1984)

7. D.I. Feldstein, Psychology of the modern teenager (Pedagogika, Moscow, 1989)

8. F.I. Salpagarova, F.O. Semenova, Bulletin of the University of the Russian Academy of education. 5, 51-58 (2018)

9. S.L. Rubinstein, Fundamentals of General psychology (Pedagogika, Moscow, 1989)

10. M.K. Mamardashvili, "As I understand philosophy" (Progress, Moscow, 1992)

11. F.O. Semenova, Family and personality: problems of interaction. 11. 78-80 (2018)

12. I.S. Kon, Psychology of early youth (Prosveshchenie, Moscow, 1989)

13. V.I. Slobodchikov, G.A. Zuckerman, Questions of psychology. 3, 25-36 (1990)

14. A.A. Rean, N.V. Bordovskaya, S.I. Rozum, Psychology and pedagogy (Piter, St. Petersburg, 2008)

15. A.V. Zakharova, G.B. Tagieva, New research in psychology. 1(34), 41-43 (1986)

16. M.M. Ebzeev, Scientific problems of humanitarian research. 1(5), 83-89 (2009)

17. L.I. Bozhovich, L.S. Slavina, Transition period from infancy to early age (Institute of practical psychology, Moscow, 1996)

18. F.I. Salpagarova, Program of formation of reflexive competence "I know myself" (Karachaevsk, 2019) 